\title{
Calculating Compensation in Cases of Wrongful Death
}

\author{
Arthur Lewbel Boston College \\ Original January 2002, revised May 2002
}

\begin{abstract}
Death statutes in the United States list elements of loss for which a defendent must make compensatory payment. The element that economists as expert witnesses are called upon to calculate is net income, roughly defined as the decedent's income minus personal expenses. The existence of joint or shared consumption goods complicates the definition and calculation of net income.

Net income can be interpreted as the money required for survivors to attain the same standard of living as before. Equivalence scales traditionally used for this type of calculation are flawed. A new method for calculating net income is proposed, based on a collective household model.
\end{abstract}

JEL codes: K1, D1, J17, C30, I31.

Keywords: Wrongful Death, Death Statutes, Adult Equivalence Scales, Consumer Demand, Household Bargaining, Insurance.

This research was supported in part by the NSF, grant SES-9905010.

Corresponding Author: Arthur Lewbel, Department of Economics, Boston College, 140

Commonwealth Ave., Chestnut Hill, MA, 02467, USA. (617)-552-3678, lewbel@bc.edu, http://www2.bc.edu/ lewbel/. 


\section{Introduction}

The concept of "net income," appears in the death statutes of some states' legal codes for the determination of compensation of surviving family members in cases of wrongful death. Economists' expert testimony in such cases is typically limited to net income calculations, which are essentially tangible, monetary losses. The final determination of compensation is then obtained by introspection on the part of a judge or jury, incorporating both net income information supplied by the economist and compensation for various intangible losses.

Roughly, net income is the income of the deceased minus his or her personal expenses. The next section provides some examples of relevant death statute language defining net income, and provides four possible interpretations of the term.

The evident intent of the law is to make net income equal the amount of money required for survivors to attain the same standard of living that they would have enjoyed if the death hadn't occured. This interpretation of net income is similar to the idea behind adult equivalence scales, that e.g. Muellbauer (1977) defines as "budget deflators which are used to calculate the relative amounts of money two different types of households require to reach the same standard of living." Numerous severe identification issues arise in the estimation of equivalence scales. See in particular Pollak and Wales $(1977,1992)$, Blundell and Lewbel (1991), and the surveys Lewbel (1997) and Slesnick (1998).

This paper proposes a general solution to the equivalence scale identification problem, suitable for the context of net income calculation. The key insight is that net income does not require comparing the standards of living of two different households. Rather, all that must be compared is the standard of living of the same individuals (the surviving family members) in two different settings, namely, by themselves and with the decedent. This distinction is related in principle to what Pollak and Wales (1977) call a situation comparison as opposed to a welfare comparison, and permits at least theoretical identification of net income given some assumptions about stability of preferences over goods.

This method of identifying net income depends on recovering the consumption demand functions of individuals within a houshold, and hence requires a collective household model. See, e.g., Bourguignon and Chiappori (1994) and Vermeulen (2000) for surveys of such models in empirical contexts. In general, constructing net income in this way assumes that the separate consumption behavior of individual household menbers can be observed, but with some additional behavioral assumptions a recent model by Lewbel, Chiappori, and Browning (2002) can be applied to construct net income from readily available consumer demand data. 
Although the focus of this paper is on net income calculations for legal purposes, the same methodology could be employed to address a range of other related issues. For example, net income is closely related to the calculation of appropriate levels of life insurance on wage earners, and may also be useful for alimony calculations. Other potential applications include social welfare analyses, and the adjustment of poverty lines for households of different sizes and compositions.

The next section discusses the legal language used to describe wrongful death compensation in some states, and proposes four possible definitions of net income based on this language. Section three then discusses other relevant legal issues, such as the complications in net income calculations that arise with the death of a child. Much of sections two and three is adapted from Lewbel and Weckstein (1995). Section four summarizes how traditional equivalence scales might be used to calculate net income, and the associated identification issues. Finally, section five proposes a feasible method of calculating net income, based on the collective household model proposed by Lewbel, Chiappori, and Browning (2002).

\section{Net Income in Death Statutes}

Death statutes generally list elements of loss for which a defendant is called upon to make compensatory payment. These can be divided into tangible and intangible components, or more precisely, into loss of income and loss of consortium or companionship. Net income is the tangible, purely monetary loss. The definition of net income depends on how one defines gross income (which is reasonably straightforward) and a household's expenses, and depends on what portion of these expenses are, or should be, attributed to the decedent. The issue of who is to receive compensation is also relevant to this calculation.

The Rhode Island death statute (10-7-1.2 Courts and Civil Procedure) defines net income as gross income minus "the estimated personal expenses that the decedent would probably have incurred for himself, exclusive of any of his dependents, over the course of his life expectancy." In some states a death award is limited to net income, as in Pennsylvania, which limits loss "to dependents... from [a decedent's] earnings... without any allowance for mental suffering, grief or loss of companionship." See Harper, James and Gray, (1986), page 598. Other states permit damages for both net income and intangibles, e.g., damages in the Massachusetts statute are for "the fair monetary value of... loss of reasonably expected net income, services, protection, care, assistance, society, companionship, comfort, guidance, counsel and advice...." (Massachusetts statutes, ch 229 S2, Massa- 
chusetts General Laws Annotated).

Given an appropriate definition of the expenses that comprise the difference between gross and net income, the calculation reduces to the more or less straightforward task of constructing a reasonable forecast or projection of gross income and of those expenses over what would have been the expected remaining natural lifetime of the decedent. The final and more difficult task of assigning a dollar value to grief, loss of companionship, and other intangibles is left to the judge and jury.

The first issue that arises in these calculations is the separation of tangibles from intangibles, since some contributions to family utility that were provided by the decedent could be purchased in the market. These range from gardening chores that are easily replaceable by a market purchase, to comfort and advice which are more difficult to replace. This line is reasonably drawn by the practical ability to present a convincing estimate of dollar value. By definition, intangibles are contributions to utility that are difficult to quantify monetarily. For example, a parent's monitoring of a child may be replaced in part by day care, but payment for day care does not fully compensate for the loss of the parent's attentions, and does not compensate at all for the loss of the parent's love and affection.

Next consider the household's expenditures. These may include services that would have been provided by the decedent and must now be purchased as above. Bequests could also be intepreted as an end of life expenditure. Given some measure of total household expenditures, the main difficulty in calculating net income is defining exactly which of these expenditures comprise the decedent's personal expenses, and hence should be subtracted from his or her gross income to yield net income.

Courts have interpreted personal expenses in different ways, without always recognizing their incompatibility. One interpretation of net income treats the damage as a loss of production. Net income then means income less the amount the producer spends to earn that income. This production interpretation of net income uses the analogy of profits from an investment project or business. The net income of a business is the receipts from the sale of product less the costs of producing the product.

This interpretation is difficult to apply satisfactorily to the loss of income of a decedent, since personal expenditures can be for both utility and income production. With profit maximization there is a relatively unambiguous meaning to the concept of costs. In contrast, a worker's personal expenses are ambiguous. There are no production forces that impinge on consumption expenses that we can rely upon to indicate what proportion of a deceased worker's consumption ex- 
penses are associated with the earning of his income. What portion of a Porsche that a manager drives to his office is an expense necessary for the production of his income? A cheaper car or perhaps public transportation would do, but the Porsche provides utility to the individual as well as contributing to income production. The investment project analog does not seem to be a promising avenue for understanding or guiding the measurement of personal expenses and hence net income.

Another possible definition of net income is income minus all personal expenses, that is, all of the income that the earner did not spend on himself or herself. This definition avoids the difficulty of determining which of the decedent's expenditures were used for producing income versus those that were for personal consumption. This definition also seems more consistent with the language used in death statutes, since the statutes do not explicitly distinguish among various types of personal expenditures. The main difficulty with defining net income in terms of all personal expenses is the treatment of joint consumption expenditures, and in particular economies of scale and scope in consumption. For example, what portion of home heating expenses should be allocated to the decedent?

The evident intent of the statute language is to allow the plaintiff, or surviving family members to "be made whole again" or to attain the same "standard of living" that they would have had if the death hadn't occured. This can be interpreted either as providing sufficient income for the survivors to purchase the same bundle of goods they (not including the decedent) would have consumed, or as providing sufficient income to purchase a bundle that is equal, in terms of utility, to the bundle that they would have consumed if the death hadn't happened.

We thus have four possible definitions of net income:

1. The decedent's gross income minus the cost of producing that income.

2. The decedent's gross income minus the cost of the bundle of goods the decedent would have consumed.

3. The income required for the survivors to consume the same bundle of goods that they would otherwise have consumed.

4. The income required for the survivors to consume a bundle of goods that provides the same standard of living or level of utility (i.e., a bundle on the same indifference curve over goods) as the bundle that they would otherwise have consumed.

The language of the death statutes sounds most like definitions 1 or 2 , but the evident intent is definitions 3 or 4 . The last definition seems most in keeping with the spirit of the law, since all compensation other than net income is interpreted as intangible and hence refers to compensation for all non monetary components 
of utility. If there were no joint consumption, then definitions 2,3 , and 4 would be identical, and the sensible conclusion would be that the courts were using 2 to attain 4 . However, the presence of joint consumption destroys this equivalence.

To illustrate, consider a married couple that owns a family car. Suppose that one fourth of the time that the car is in use consists of the husband driving it to work alone (contributing to income production). Another fourth is the husband driving alone but not to work (husband's consumption), another fourth is the wife driving alone (wife's consumption), and the final fourth is both riding together (shared or joint consumption). To compensate the wife for the death of the husband, when calculating net income by definition 1, one fourth of the cost of gasoline would be subtracted from gross income. By definition 2, three fourths would be subtracted, by definition 3 one half would be subtracted, and by definition 4 somewhat more than one half would likely be subtracted. In this last case the effective price of transportation per mile for the wife is higher after the husband's death because the savings from shared consumption are lost, but without more information we cannot say exactly what the correct expense adjustment would be, since it will also depend on the relative changes in effective prices of other jointly consumed goods.

A feasible method of accounting for joint consumption and thereby calculating net income by either definitions 2,3 , or 4 , will be provided later.

\section{Death of a Child and Other Complications}

The presence of joint consumption, and more generally the notion that compensation is intended to make its beneficiaries "whole" again, means that the correct definition of net income will depend in part on attributes, and hence identities, of the beneficiaries. For example, the appropriate allocation of joint expenses, and hence the magnitude of net income, might depend in part on whether the decedent were a member of a small family or a large one.

This issue, and other legal complications associated with the calculation of net income, are particularly stark in the example of the death of a child. While the nature of the intangible losses may differ, the separation of compensation for net income versus intangibles is essentially the same as for an adult, where (in some states) an award is made to surviving parents for pain and suffering, separate from any possible income the child might have earned. See Harper, James and Gray (1986), page 601.

Before the child is grown, he or she contributes little or no income to the 
family, so the child's net income is essentially zero minus the "personal expenses of the child." The calculation of a child's net income is therefore related to the goals of the literature on calculating the costs of children. See Browning (1992) and Blackorby and Donaldson (1994) for surveys.

In addition, net income is a lifetime calculation. It is presumed that the child would have grown up and had an income in the future. How should that income be considered in compensation? Calculating total net income requires a projection of the income the child would have earned over the course of his or her life. The child's prospective household over his or her working life must also be projected (presumably based on some demographic probabilities), because the share of income allocated to personal expenses is affected by family size and composition, which would itself likely vary over time.

The striking feature of this calculation is that it includes compensation for those who, because of the premature death of the decedent, will never in fact be beneficiaries. Massachusetts law requires compensation to those who would benefit from the lost income of the decedent, to the extent they would have expected to receive benefits (Massachusetts statutes, ch 229 S2, Massachusetts General Laws Annotated), and so in Massachusetts no compensation is paid for these virtual, or spectral, beneficiaries. However, in other jurisdictions, such as Rhode Island, the defendant is liable for the full net income loss, even the part that would have benefited a merely conceptual survivor (Rhode Island death statute 10-7-1.2, Courts and Civil Procedure).

Related issues arise in the treatment of remarried spouses. A new spouse may in some sense be an adequate replacement of the decedent (at least with respect to income). The new spouse might fill this role before the culmination of the tort suit so that the question of making the survivors whole becomes hypothetical. In such cases a loss is still presumed to have occurred, and net income is calculated as before. When a loss has already been compensated by another means, the issue of double compensation is disposed of by the "collateral-source rule" (Harper, James and Gray, 1986, pages 604-5). This is usually applied to cases where compensation has been made by an insurance payment. Although remarriage is not quite insurance, in that the plaintiff does not remarry by previous contract, the justification for this rule, to prevent the defendant from "setting up [an] insurance policy as a bar to action [which] would result in underdeterrence," (Posner, 1986) may still reasonably apply to remarriage.

Another issue regarding making survivors 'whole' is that net income could be negative, as in the case of a child when losses to spectral beneficiaries are excluded, or when the decedent was a secondary wage earner that consumed more 
than he or she contributed to the household's assets. Based on underdeterence arguments analogous to those of the previous paragraph, it is appropriate in such circumstances to treat net income as zero.

\section{Traditional Equivalence Scales}

Equivalence scales are defined as the income required by one household to be "as well off" as another. The early equivalence scale literature attempted to define this ratio of costs of living directly in terms of measurable quantities such as the costs of acquiring a required number of calories, but this was soon replaced by defining households to be equally well off if they attain an equal level of utility (see, e.g., Lewbel 1997 and Pollak and Wales 1992 for surveys). Just as a true cost of living price index measures the ratio of costs of attaining the same utility level or indifference curve under different price regimes, equivalence scales are supposed to measure the ratio of costs of attaining the same utility level or indifference curve under different household compositions.

Let $U^{i}\left(x^{i}\right)$ denote the utility function describing the preferences of household $i$, where $x^{i}$ is the vector of quantities of goods consumed by household $i$. If we think of $i$ as indexing household composition, then $U^{i}$ is what Pollak and Wales (1992) refer to as a "conditional" utility function, that is, it describes a household's preferences conditional on the household having a certain composition. This is in contrast to an unconditional utility function, which describes preferences over both goods and composition.

Let $p$ be the vector of prices of goods, and let $i=c$ denote a reference household, in this case, a married couple. The traditional equivalence scale for some other household, say $i=f$ (denoting a female, possibly a single mother with children) is defined as

$$
s^{f}=\min _{\widetilde{x}}\left\{p^{\prime} \tilde{x} \mid U^{f}(\widetilde{x})=U^{c}\left(x^{c}\right)\right\} / p^{\prime} x^{c}
$$

which equals the minimum expenditure level required by household $f$ to attain the same utility level as household $c$, divided by the total expenditures of household $c$. To use this equivalence scale to calculate net income in the example where the decedent was a wage earning husband, one would multiply the couple's gross income by $s^{f}$, This would then be the income required to give the now smaller household the same level of utility that it would have had without the death (adjustments for savings and for income generated by survivors are discussed later). 
There are many obstacles, both conceptual and practical, to implementing this procedure. Some sort of separability of tangibles $x$ from intangibles must be assumed, and each utility function $U^{i}$ must be interpreted as the utility that is only due to consumption, not intangibles. Preferences must be recovered from observed demands. We do not literally observe the demands of the decedent's household in all possible price regimes, so demand functions must instead be estimated from survey data of demographically similar households.

The most serious obstacle to applying the equivalence scale methodology is that, by revealed preference theory, from demands for goods one can only recover indifference curves, not actual levels of utility. Consider two commodity space graphs, one consisting of all of the indifference curves over bundles of goods according to the preferences of household $f$, and the other consisting of all of the indifference curves over bundles of goods according to the preferences of household $c$. The numbering of indifference curves in either of these graphs is arbitrary (equivalently, by ordinality preferences are unaffected by applying monotonic transformations to the functions $\left.U^{i}\right)$, but equating $U^{f}(x)$ to $U^{c}\left(x^{c}\right)$ requires that we know the unique one to one mapping that equates each indifference curve in one graph to an indifference curve in the other graph that delivers the same level of utility (see Pollak and Wales 1992, p. 86). No information about this mapping is identified from each household's separate demands, so equivalence scales themselves are not identified. Many schemes have been proposed to overcome this identification problem (see Lewbel 1997 for a survey), but ultimately all require extensive untestable and unoservable assumptions regarding comparability of preferences.

In some circumstances one might gain additional information from unconditional demands, by applying some form of revealed preference theory over household composition as well as over goods. This is difficult because household composition is not priced the way goods are, but even if this obstacle could be surmounted in some contexts, it will clearly not work for cases of wrongful death, because the household without the decedent results from tragedy rather than arising by choice.

Yet another difficulty with basing net income calculations on traditional equivalence scales is that a household may not possess a well defined utility function, but may instead use some kind of bargaining process to determine its purchases. In this case there will not exist a utility level for the household, and hence no equivalent scale would exist by the traditional definition of equation (1). 


\section{A New Method for Calculating Net Income and Equivalence Scales}

Traditional equivalence scales require a comparison of the utilities of different households. When applied to net income calculations, these are the household with the decedent and the household without. However, the definitions of net income do not actually call for this comparison. Rather, net income is only required to make the survivors "whole." This means that, rather than comparing two different households, net income only requires comparing the utility or the consumption of the exact same individual or group of people (the surviving household members) in two different environments. Thus, unlike equivalence scales, net income does not require utility comparisons across different individuals or groups, and so is potentially identifiable without untestable assumptions regarding comparability of utility across individuals.

To make this distinction concrete, consider for simplicity the case of a childless married couple where only the husband works and there is no saving and no joint or shared consumption. Let $U^{f}\left(x^{f}\right)$ and $U^{m}\left(x^{m}\right)$ be the utility functions of the female and male respectively, consuming bundles $x^{f}$ and $x^{m}$. The couple has gross income which equals total expenditures $y$, and chooses consumption bundles $x^{f}$ and $x^{m}$ by

$$
\max _{x^{f}, x^{m}}\left\{\widetilde{U}\left[U^{f}\left(x^{f}\right), U^{m}\left(x^{m}\right)\right] \mid p^{\prime}\left(x^{f}+x^{m}\right)=y\right\}
$$

Where $\widetilde{U}$ is either a social welfare function or a bargaining function that is increasing in $U^{f}$ and $U^{m}$, and could itself depend directly on $y, p$, or other variables that affect the relative bargaining power of the husband and wife.

The function $\widetilde{U}$ may also be assumed to embody intangible contributions to utility, such as those arising from consortium or companionship. Formally, the attained utility levels of the husband and wife may be functions of $U^{f}\left(x^{f}\right)$, $U^{m}\left(x^{m}\right)$, and various intangibles, and the bargaining or social welfare function for the household would in turn be functions of these attained utility levels and of variables that affect bargaining power.

In this example, the consumption bundles of each houshold member are made explicit, and it can be immediately seen that, by definition 2 net income $\tilde{y}$ is given by

$$
\tilde{y}=y-p^{\prime} x^{m}
$$

by definition 3 net income is

$$
\tilde{y}=p^{\prime} x^{f}
$$


and by definition 4 net income is

$$
\tilde{y}=\min _{x^{*}}\left\{p^{\prime} x^{*} \mid U^{f}\left(x^{*}\right)=U^{f}\left(x^{f}\right)\right\} .
$$

In this example having no joint consumption, these three definitions are all numerically identical.

Compare these straightforward results to the use of traditional equivalence scales. This would first require assuming that the component of $\widetilde{U}\left[U^{f}\left(x^{f}\right), U^{m}\left(x^{m}\right)\right]$ that only describes utility over tangibles be identified and expressed as $U^{c}\left(x^{c}\right)$ for some function $U^{c}$, where $x^{c}=x^{f}+x^{m}$ is the total consumption bundle of the couple $c$. It would then be assumed that appropriate cardinalizations of the functions $U^{c}$ and $U^{f}$ can be chosen or found that are interpersonally comparable (see Lewbel 1989), and would finally define net income as $\min _{\tilde{x}}\left\{p^{\prime} \widetilde{x} \mid U^{f}(\widetilde{x})=U^{c}\left(x^{c}\right)\right\}$, thereby giving the wife alone the same level of utility over goods that the couple would have had.

This traditional equivalence scale attempts to answer the question, "how much income would a single individual need to attain the same utility level as a household?" However, for many applications, including calculation of net income, the appropriate questions to ask are, "how much income would an individual living alone need to attain the same indifference curve, or to consume the same bundle, that the same individual attained or consumed as a member of the household?" These latter questions avoid issues of interpersonal comparability and hence are at least in principle answerable from revealed preference data.

Now consider making the collective household model in equation (2) more realistic. First, the model can be extended to handle situations in which there is more than one survivor, most easily by redefining $U^{f}$ as a joint utility or social welfare function of all the survivors, e.g., the joint utility function of a wife and her children. Next, savings can be handled by separately considering the husband's gross income $I^{m}$, the wife's gross income $I^{f}$, and total expenditures $y$. After calculating net income based on $y$, one may simply add $I^{m}-I^{f}-y$ to the result. Applying this calculation over the projected lifetime of the decedent essentially assumes that net income includes money that would have been used by the decedent as a bequest, which is reasonable because generally the survivors would be the decedent's intended recipients of any bequest.

The difficult extension is dealing with joint or shared consumption. Following Lewbel, Chiappori, and Browning (2002), define a consumption technology function $F$ that relates the bundle of goods consumed by the household, say $z$, to a vector of private good equivalents $x$. These private good equivalents are then 
divided up between the household members, with each member deriving utility from consuming their share of $x$. The proposed model of household consumption is then

$$
\max _{x^{f}, x^{m}}\left\{\widetilde{U}\left[U^{f}\left(x^{f}\right), U^{m}\left(x^{m}\right)\right] \mid p^{\prime} F\left(x^{f}+x^{m}\right)=y\right\}
$$

where $z=F\left(x^{f}+x^{m}\right)$ is the bundle of goods that the household is observed purchasing. Because of joint consumption in the household, buying the bundle $z=F(x)$ with sharing is equivalent to buying the bundle $x=x^{f}+x^{m}$ without sharing.

This framework is similar to a Becker (1965) type household production model, except that instead of using market goods to produce commodities that contribute to utility, the household essentially produces the equivalent of a greater quantity of market goods via sharing. This is essentially the motivation for Barton (1964) type equivalence scales and Gorman's (1976) linear household technologies, except that a collective model of the household is employed to account for the differences in preferences of the different household members.

The transformation from $z$ to $x$ embodied by the function $F$ is intended to summarize all of the technological economies of scale and scope that result from living together. For a purely private good $k$ for which there is no shared consumption, e.g., clothing, $x_{k}$ could equal $z_{k}$. For a good $k$ that is shared, e.g., automobile use, $x_{k}$ might equal $f_{k} z_{k}$, where $f_{k}-1$ represents the fraction of time that the good is consumed jointly. More generally $f_{k}$ could be an arbitrary function of $z$, implying that the fraction of time that the car is consumed jointly depends on the total quantity of car use, and on the quantity of other goods, e.g., vacations and food consumed away from home.

This model makes explicit the otherwise implicit (because of sharing) consumption bundles of each houshold member, and thereby permits calculation of the various definitions of net income. As before, net income is, depending on its definition, given by equation (3), (4), or (5) (before adjusting for savings and multiple incomes), but now these definitions are all numerically different. Definition 3 can be written in a form that looks like total expenditures minus husbands expenses (analogous to definition 2 and the language of the death statutes), if instead of actual total expenditures $y=p^{\prime} z$ we use the "no sharing" equivalent expenditures $y^{*}=p^{\prime} x$. Then by definition 2 net income is $y-p^{\prime} x^{m}$ while by definition 3 net income equals $y^{*}-p^{\prime} x^{m}$.

In terms of making the survivors "whole," definition 2 undercompensates the survivors, since for any good that is mostly or entirely shared (e.g., home heating), almost the entire cost of that good will be subtracted from gross income and hence 
excluded from net income. In contrast, definition 3 provides enough income for the survivors to buy the same bundle $x^{f}$ that they implicitly would have consumed without the death. This could be interpreted as an overcompensation, since the bundle $x^{f}$ that would have been obtained in part through sharing will no longer be most economical when purchased directly. By exploiting substitution effects, net income by definition 3 allows the survivors to attain a higher indifference curve over goods, and hence a higher standard of living, than they would have attained as members of the household that included the decedent. Definition 3 yields a net income measure somewhere in between that of definitions 2 and 4, and best accords with the notion of providing the survivors the same standard of living that they would have attained without the death.

In summary, definition 2 is closest to a narrow reading of the language of the statutes but is least generous, clearly undercompensating the survivors for shared consumption. Definition 4 seems closest to the likely intent of the statutes in defining net income, and Definition 3, which is the most generous, is somewhere between these other two with regard to the language of the statutes. Unlike equivalence scale based methods, the proposed model of household consumption based on equation (6) permits an unambiguous calculation of net income by whichever definition a court might deem appropriate.

\section{Implementing the Model}

Although it avoids identification issues associated with interpersonal comparability, implementing the model of equation (6) requires that, from observed data, we be able to recover $x^{m}, x^{f}$ and/or $x^{*}$ associated with current and projected future price and income regimes $p, y$. We cannot actually observe the behavior of the decedent's household before the death in different price and income regimes, so this information must instead be estimated from survey data. In theory, the consumption of individual household members, and hence $x^{f}$ and $x^{m}$ as well as $z$, could be observed in surveys encompassing different price and income regimes. It follows from applying the second welfare theorem to equation (6) that there exist shadow prices and incomes such that, in this model, each member $i$ (for $i=m$ and $i=f$ ) chooses the consumption bundle $x^{i}$ to maximize $U^{i}\left(x^{i}\right)$ subject to a personal budget constraint, so given observation of these personal consumption quantities, revealed preference theory could be used to recover the required estimates.

In practice, virtually all existing household consumption data sets, such as the 
US consumer expenditure survey, only record the purchases $z$ of households, and not the individual household member's consumption vectors $x^{f}$ and $x^{m}$. However, by making some assumptions about stability of preferences over goods, the model can be identified and estimated by combining data from different households. To demonstrate these estimation methods, consider the following example, which is a special case of the more general collective household model by Lewbel, Chiappori, and Browning (2002).

Let $U^{i}\left(x^{i}\right)=U\left(x^{i} \mid \theta^{i}\right)$ denote a parameterization of the individual member's utility functions, where $\theta^{i}$ is a vector of parameters. Let

$$
z^{i}=h\left[p, y^{i} \mid \theta^{i}\right]
$$

denote the demands that would arise from maximizing the utility function $U\left(z^{i}\right.$ | $\theta^{i}$ ) subject to the budget constraint $p^{\prime} z^{i}=y^{i}$. Assume the household's consumption technology function $F$ is linear and homogeneous, so

$$
z=A x
$$

for some square matrix $A$. If $A$ is a diagonal matrix, then this closely resembles a Barten (1964) type technology. Assume the bargaining or social welfare function $\widetilde{U}$ of the household is such that the wife (or wife plus children) controls a fraction $\eta$ of "no sharing" equivalent expenditures $y^{*}=p^{\prime} x$, so $y^{f}=\eta y^{*}$ and $y^{m}=$ $(1-\eta) y^{*}$. It then follows (see Lewbel, Chiappori, and Browning (2002) for details) that the household's demands are given by

$$
z=A h\left[A^{\prime} p, \eta y \mid \theta^{f}\right]+A h\left[A^{\prime} p,(1-\eta) y \mid \theta^{m}\right]
$$

and the private goods equivalents for each household member are

$$
\begin{gathered}
x^{f}=h\left[A^{\prime} p, \eta y \mid \theta^{f}\right] \\
x^{m}=h\left[A^{\prime} p,(1-\eta) y \mid \theta^{m}\right]
\end{gathered}
$$

If the private consumption vectors $x^{f}$ and $x^{m}$ of individual household members are observed along with the household's purchases $z$, then the parameters $\theta^{f}, \theta^{m}, A$, and $\eta$ can be estimated using equations (9), (10), and (11). Depending on the functional form of $h$, it may be possible to identify and estimate these parameters by observing the private consumption quantities $x_{k}^{f}$ and $x_{k}^{m}$ of only a few goods, for example, it is reasonable to assume that clothing is privately consumed, so we may let $x_{k}^{f}=z_{k}$ and $x_{k}^{m}=0$ for the good $k$ corresponding to women's clothes. 
Alternatively, we may use the ordinary consumption data on singles living alone to estimate the parameters $\theta^{f}$ and $\theta^{m}$ using equation (7) for $i=m$ and $i=f$, along with household data in equation (9) to identify $A$, and $\eta$, although this requires assumptions about some preferences over goods not changing by marriage.

It is common to estimate demand equations in budget share form. For each $\operatorname{good} k$, let

$$
p_{k} z_{k}^{i} / y^{i}=\omega_{k}^{i}\left[p, y^{i} \mid \theta^{i}\right]
$$

be the budget share of good $k$ that would arise from maximizing the utility function $U\left(z^{i} \mid \theta^{i}\right)$ subject to the budget constraint $p^{\prime} z^{i}=y^{i}$. It then follows from equations (7) and (9) that the budget shares of the household's purchases have the simple form

$$
p_{k} z_{k} / y=\eta \omega_{k}^{f}\left[A^{\prime} p, \eta y \mid \theta^{i}\right]+(1-\eta) \omega_{k}^{m}\left[A^{\prime} p,(1-\eta) y \mid \theta^{i}\right]
$$

which is just a weighted average of budget share equations of the household members, with weights given by the income sharing rule $\eta$. These equations could prove easier for estimation, using some popular model like the Translog or Almost Idead Demand System for the functions $\omega_{k}^{i}\left[p, y^{i} \mid \theta^{i}\right]$.

Given these estimates, for any price and total expenditure levels $p$ and $y$, net income $\tilde{y}$ for the surviving member(s) $f$ (before adjusting for savings and multiple incomes) is given by

$$
\tilde{y}=y-p^{\prime} h\left[A^{\prime} p,(1-\eta) y \mid \theta^{m}\right]
$$

and by definition 3 net income would be

$$
\tilde{y}=p^{\prime} h\left[A^{\prime} p, \eta y \mid \theta^{f}\right]
$$

To calculate net income by definition 4 , let $V\left(p, y^{i} \mid \theta^{i}\right)=U\left(h\left[p, y^{i} \mid \theta^{i}\right] \mid\right.$ $\theta^{i}$ ) denote the indirect utility function corresponding to the direct utility function $U\left(z^{i} \mid \theta^{i}\right)$. Net income by definition 4 is then the number $\tilde{y}$ that satisfies

$$
V\left(p, \tilde{y} \mid \theta^{f}\right)=V\left(A^{\prime} p, \eta y \mid \theta^{f}\right)
$$

It may be for a judge to decide which of these definitions should be applied, but as has been argued earlier, based on the intent of the law to make the survivor's "whole" with regards to tangibles, definition 4 would seem most appropriate.

By whatever definition is used, the resulting $\tilde{y}$ must be adjusted to account for savings and for both member's having incomes by adding $I^{m}-I^{f}-y$ to $\tilde{y}$, 
where $I^{i}$ is the gross income of member $i$. Finally, the resulting net income must be forecasted over the expected remaining lifetime of the decedent (this might be done by forecasting the various components $I^{m}, I^{f}, y$, and $p$ ), and the present discounted value of the result would then be the total net income required.

\section{Conclusions}

In cases of wrongful death, potential compensation for the surviving family members is divided into tangible monetary losses, summarized by net income, and intangible losses associated with loss of companionship, grief, etc.,. Four different interpretations of net income were proposed, each of which may be consistent with the letter or the intent of the law. Given the implied welfare or standard of living comparisons associated with the interpretation of net income as making the survivors 'whole' or 'as well off economically' as before, equivalence scales would seem to provide an appropriate framework for estimating net income. However, traditional equivalence scale models suffer from severe identification problems by requiring interpersonally comparable utility. An alternative, collective model of household behavior is proposed that overcomes these identification problems, and provides a more appropriate framework for estimating net income.

This same framework may be more generally applicable to problems regarding income and welfare that in the past have been addressed using traditional equivalence sacles. For example, Jorgenson and Slesnick (1987) use equivalence scales to adjust measures of income inequality in the United States to account for variations in household size and composition. One could alternatively use the collective household model of equation (6) to calculate the equivalent income of each member of the household, and then construct income inequality measures directly over all the individuals in the population, rather than over households. This framework might also be used to construct measures of household economies of scale under less restrictive assumptions than other models (see, e.g., Nelson 1988 and references therein) by, e.g., comparing the relative values of $y$ and $y^{*}$.

Other potential applications of this methodology might include estimation of reasonable levels of life insurance on wage earners, and the adjustment of poverty lines to account for households of different sizes and compositions. 


\section{References}

[1] Barton, A. P., 1964. Family Composition, Prices, and Expenditure Patterns. in Econometric Analysis for National Economic Planning: 16th Symposium of the Colston Society, P. Hart, G. Mills, and J. K. Whitaker, eds., 277-292, London: Butterworth.

[2] Becker, G., 1965. A Theory of the Allocation of Time. Economic Journal 75, 493-517.

[3] Blundell, R. and A. Lewbel, 1991. The Information Content of Equivalence Scales. Journal of Econometrics 50, 49-68.

[4] Blackorby, C. and D. Donaldson, 1994. Measuring Costs of Children: A Theoretical Framework. in The Measurement of Household Behavior, R. Blundell, I. Preston, and I. Walker, Eds., 70-85, Cambridge: Cambridge University Press

[5] Bourguignon, F. and P.-A. Chiappori, 1994. The Collective Approach to Household Behavior. in The Measurement of Household Behavior, R. Blundell, I. Preston, and I. Walker, Eds., 70-85, Cambridge: Cambridge University Press

[6] Browning, M., 1992. Children and Household Economic Behavior. Journal of Economic Literature 30, 1434-1475.

[7] Gorman, T., 1976. Tricks With Utility Functions. In Essays in Economic Analysis: Proceedings of the 1975 AUTE Conference, Sheffield, M. J. Artis and A. R. Nobay, eds., Cambridge: Cambridge University Press.

[8] Harper, F.V., F. James and O. S. Gray, 1986. The Law of Torts, 2nd ed., Boston: Little, Brown.

[9] Jorgenson, D. W., and D. T. Slesnick, 1987. Aggregate Consumer Behavior and Household Equivalence Scales. Journal of Business and Economic Statistics 5, 219-232.

[10] Lewbel, A., 1989. Household Equivalence Scales and Welfare Comparisons. Journal of Public Economics 39, 377-391. 
[11] Lewbel, A., 1997. Consumer Demand Systems and Household Equivalence Scales. Handbook of Applied Econometrics, Volume II: Microeconomics, M. H. Pesaran and P. Schmidt, eds., Oxford: Blackwell Publishers Ltd.

[12] Lewbel, A, P.-A. Chiappori, and M. Browning, 2002. Estimating Consumption Economies of Scale, Adult Equivalence Scales, and Household Bargaining Power. unpublished Boston College manuscript.

[13] Lewbel, A, and R. Weckstein, 2002. Equivalence Scales, Costs of Children, and Wrongful Death Laws. Journal of Income Distribution 4, 191-208.

[14] Muellbauer, J., 1977. Testing the Barten Model of Household Consumption Effects and the Cost of Children. Economic Journal 87, 460-487.

[15] Nelson, J. A., 1988. Household Economies of Scale in Consumption: Theory and Evidence. .Econometrica 56, 1301-1314.

[16] Pollak, R. A. and T. J. Wales, 1979. Welfare Comparisons and Equivalence Scales. American Economic Review 69, 216-221.

[17] Pollak, R. A. and T. J. Wales, 1992. Demand System Specification and Estimation, Oxford: Oxford University Press.

[18] Posner, R. S.,, 1986. Economic Analysis of the Law, 3rd ed, Aspen: Aspen publishers inc.

[19] Slesnick, D., 1998. Empirical Approaches to the Measurement of Welfare. Journal of Economic Literature 36, 2108-2165.

[20] Vermeulen, F., 2000. Collective Household Models: Principles and Main Results. Center for Economic Studies, University Leuven, Discussion Paper. 